"This accepted author manuscript is copyrighted and published by Elsevier. It is posted here by agreement between Elsevier and MTA. The definitive version of the text was subsequently

published in [Applied Surface Science, 2018, 453, 245-251; DOI 10.1016/j.apsusc.2018.05.064]. Available under license CC-BY-NC-ND." 


\title{
Preparation of Graphene Oxide/Semiconductor Oxide Composites by Using Atomic Layer Deposition
}

\section{Nóra Justh ${ }^{1}$, Barbara Berke ${ }^{2}$, Krisztina László ${ }^{2}$, László Péter Bakos ${ }^{1}$; Anna Szabó ${ }^{3}$, Klára Hernádi $^{3}$, Imre Miklós Szilágyi ${ }^{{ }^{*}}$}

${ }^{1}$ Department of Inorganic and Analytical Chemistry, Budapest University of Technology and Economics, H-1111 Budapest, Szt. Gellért tér 4. Hungary;

${ }^{2}$ Department of Physical Chemistry and Materials Science, Budapest University of Technology and Economics, P.O. Box 92, H-1521 Budapest, Hungary;

${ }^{3}$ Department of Applied and Environmental Chemistry, University of Szeged, Szeged, 6720, Rerrich B. ter 1, Hungary

Corresponding author: imre.szilagyi@mail.bme.hu

\begin{abstract}
$\mathrm{TiO}_{2}, \mathrm{Al}_{2} \mathrm{O}_{3}$ and $\mathrm{ZnO}$ are grown by atomic layer deposition (ALD) at $80{ }^{\circ} \mathrm{C}$ on graphene oxide (GO), synthesized by the improved Hummers method. The preparation steps and the products are followed by FTIR, Raman, TG/DTA-MS, SEM-EDX, XRD and TEM-ED. Both $\mathrm{Al}_{2} \mathrm{O}_{3}$ and $\mathrm{TiO}_{2}$ grown with ALD are amorphous, while $\mathrm{ZnO}$ is crystalline. Through decomposing methylene orange by UV irradiation it is revealed that the GO itself is an active photocatalyst. The photocatalytic activity of the amorphous $\mathrm{TiO}_{2}$, deposited by low temperature ALD, is comparable to the crystalline $\mathrm{ZnO}$ layer, which is the best photocatalyst among the studied
\end{abstract}


oxides. $\mathrm{Al}_{2} \mathrm{O}_{3}$ used as reference suppresses the photocatalytic performance of the $\mathrm{GO}$ by blocking its active surface sites.

Keywords: Graphene oxide, $\mathrm{TiO}_{2}$, Amorphous, Composite, ALD, Photocatalysis

\section{Introduction}

Photocatalytic composites have great potential in the field of environmental remediation, water splitting and self-cleaning surfaces [1,2]. Among the various semiconductor oxide photocatalysts, $\mathrm{TiO}_{2}$ being stable and non-toxic is the most widely studied due to its ideal band gap width for both half reactions of water splitting [3-5]. However, its use still faces the difficulty of its narrow light response range limited to UV [2,6,7]. Among others, its composites with semiconductor-oxides or other nanomaterials, such as carbon nanostructures, may enhance the photocatalytic activity. The inhibition of recombination by promoting the charge separation, the widening of the wavelength response range and the modifying the photocatalytic selectivity are three advantages of $\mathrm{TiO}_{2}$ composites [8-11]

Carbon-based nanomaterials, such as fullerene, carbon nanotubes (CNTs), carbon nanospheres, graphene, graphene oxide (GO) or carbon aerogels are very attractive substrates for $\mathrm{TiO}_{2}$ composites, due to their high surface area, good thermal and electrical properties, and mechanical as well as chemical stability [12]. There are several ways how $\mathrm{TiO}_{2}$ and other semiconductor oxides can be deposited on carbon substrates (e.g. sol-gel synthesis, CVD, sputtering) [13-18]. Atomic layer deposition (ALD) is an outstanding tool as it allows the coating of complex and high surface area nanostructures in a conformal and homogeneous 
manner, with a precise control of the grown film thickness at nanometer scale [19-21].There have been several ALD depositions on carbon substrates previously. The majority of them were done on CNTs [19]; however, there have been also attempts on graphene and graphene oxide. These latter studies involved depositing oxides (e.g. $\mathrm{A}_{2} \mathrm{O}_{3}$ [22]; $\mathrm{TiO}_{2}$ [23-30]) and metals (e.g. Pt [31]). The application of these composites included electrocatalysis [24], ion detection [31], Li battery electrodes [25,29], transistors [26]. Photocatalytic properties were only scarcely studied, and in this case $\mathrm{TiO}_{2}$ was grown in crystalline (anatase) form onto $\mathrm{GO}$ [24]. The photocatalytic performance of ALD grown amorphous $\mathrm{TiO}_{2} / \mathrm{GO}$ composites were not studied; however, recently it was shown that an amorphous $\mathrm{ALD} \mathrm{TiO}_{2} /$ fullerene composite had remarkable photocatalytic activity [32].

As substrates for ALD growth, the main disadvantage of the carbon substrates is that the direct deposition of oxide layers is challenging due to the chemical inertness of the surface. The films can typically nucleate only at defect sites or at functional groups. In the case of graphene, this can be overcome by using an $\mathrm{NO}_{2}$ layer first, which binds to the graphene as a Lewis base, and it serves as nucleation center for further ALD growth of other materials [24]. On the other hand, the GO exhibits a rich surface chemistry, as the graphene sheet is functionalized with chemically reactive carboxyl, hydroxyl and epoxy groups, which makes ALD growth much easier on GO than on graphene [33]. Due to these, GO also has attractive tunable electronic, magnetic and optoelectronic properties. Introduction of functional groups into the graphene lattice partially disrupts the in-plane symmetry of the carbon $\pi$-network and induces an optoelectronic bandgap in the electronic structure resulting in semiconducting GO [34,35]. This semiconductor behavior of GO might mean that GO in itself has photocatalytic activity; however, this is still a subject of debates $[11,34,35]$. The reason for the controversy can be that the exact composition and hence 
the electric properties of GO strongly depend on the way of preparation. Therefore, the previously studied GO samples might have had small differences in their properties, and thus they could show diverse activities. This underlines the importance of a detailed characterization of GO prior to its application. [16,36-38] Hence, this study reports the synthesis of GO by the improved Hummers' method, and the ALD growth of $\mathrm{TiO}_{2}, \mathrm{ZnO}$ and $\mathrm{Al}_{2} \mathrm{O}_{3}$ layers on the GO substrate at low temperature $\left(80^{\circ} \mathrm{C}\right)$. The as-prepared materials are studied by Fourier transform infrared spectroscopy (FTIR), Raman spectroscopy, simultaneous thermogravimetry and differential thermal analysis coupled on-line with mass spectrometry (TG/DTA-MS), scanning electron microscopy (SEM) with energy dispersive X-Ray analysis (EDX), X-ray powder diffraction (XRD) and transmission electron microscopy with electron diffraction (TEM-ED). The photocatalytic activity of bare GO and GO/oxide composites are also tested, which allows to determine whether GO has photocatalytic effect on its own and to compare the interaction of GO with the ALD deposited photocatalytically active and non-active oxides. The low temperature ALD growth resulted in amorphous $\mathrm{TiO}_{2}$, which enabled to investigate the possible photocatalytic effect of $\mathrm{GO} /$ amorphous $\mathrm{TiO}_{2}$ composite. As reference, $\mathrm{ALD} \mathrm{ZnO}$ is selected as photocatalytically active crystalline semiconductor oxide, while $\mathrm{Al}_{2} \mathrm{O}_{3}$ as an inactive oxide photocatalyst.

\section{Results and discussion}

According to the SEM images, both the GO and the GO/oxide composites are present in micrometer scale flakes (Figure S1). EDX measurements show that the ALD doped GO composites contain only $\mathrm{C}, \mathrm{O}$ and $\mathrm{S}$ atoms and the corresponding metals from the ALD grown 
oxides (Table 1 and Table S1). The graphite starting material had 0.01 atom $\% \mathrm{~S}$; therefore, the great majority of sulfur present in GO is the result of the exfoliation reaction. The $\mathrm{Al}$ and $\mathrm{Zn}$ content of the composites is 11.9 and 10.1 atom $\%$, respectively, meaning that the amount of $\mathrm{ZnO}$ is ca. $25 \%$ larger than the $\mathrm{Al}_{2} \mathrm{O}_{3}$ content; nevertheless, they are in the same order of magnitude. In contrast, even though we raised the number of the ALD cycles from 100 to 250 when depositing $\mathrm{TiO}_{2}$, much less $\mathrm{Ti}$ is detected (0.75 atom \%) on the GO, because the $\mathrm{TiO}_{2}$ growth rate is lower [39].

The vibration bands belonging to the carbon GO support are at $3030 \mathrm{~cm}^{-1}$ (aromatic $-\mathrm{CH}$ ), $3080 \mathrm{~cm}^{-1}(=\mathrm{CH}), 1650 \mathrm{~cm}^{-1}(\mathrm{C}=\mathrm{C}), 1400 \mathrm{~cm}^{-1}(=\mathrm{C}-\mathrm{H})$ and $900 \mathrm{~cm}^{-1}$ (-CH deformation) (Figure 2) $[40,41]$. The bands of the functional groups of GO are also visible in the FTIR spectra. The main stretching bands of the carboxyl and epoxy groups in the GO are at $1725 \mathrm{~cm}^{-1}(\mathrm{C}=\mathrm{O})$ and $1050 \mathrm{~cm}^{-1}(\mathrm{C}-\mathrm{O})$. The band at $1250 \mathrm{~cm}^{-1}$ (-C-O-C) are assigned to the epoxy mode of the lactone group. The wide stretching hydroxyl band appears at $3400 \mathrm{~cm}^{-1}$ and the $\mathrm{OH}$ deformation band is also present at $1400 \mathrm{~cm}^{-1}$. As the GO sample contains sulfonyl functional groups [42], the corresponding stretching vibration bands are also visible at $1250 \mathrm{~cm}^{-1}\left(\mathrm{SO}_{2}\right.$ asymmetric) and $1100 \mathrm{~cm}^{-1}\left(\mathrm{SO}_{2}\right.$ symmetric $)$.

When oxides are grown on the GO by ALD, they can be associated with the lattice vibration bands under $1000 \mathrm{~cm}^{-1}$ [43-45]. Al-O stretching bands are between $900-400 \mathrm{~cm}^{-1}$, i.e. the 900 $700 \mathrm{~cm}^{-1}$ region is assigned to tetrahedral $\mathrm{AlO}_{4}$, and the proposed characteristic frequencies of octahedral $\mathrm{AlO}_{6}$ are between $750-400 \mathrm{~cm}^{-1}$ [46-48]. The $\mathrm{Zn}-\mathrm{O}$ stretching vibration is at around $400 \mathrm{~cm}^{-1}[49,50]$. In the $\mathrm{TiO}_{2}$ composite spectra, due to the low amount of $\mathrm{TiO}_{2}$, only smaller peaks are visible around $600 \mathrm{~cm}^{-1}[9,51,52]$. Hence, FTIR spectra also confirm that the ALD process was successful with all the oxides on GO. The intensity of the bands belonging to the 
carbon functional groups decreases after the ALD; e.g. it is clearly visible in the case of the 1725 $\mathrm{cm}^{-1}(-\mathrm{C}=\mathrm{O})$ band. However, the $\mathrm{OH}$ vibration bands are exceptions: after the ALD deposition these bands are as intensive as before. On the one hand, the ALD process uses up the $\mathrm{OH}$ functional groups; on the other hand, new hydroxyl groups appear on the surface of the new oxide layers.

Figure 2a shows the TEM image of the $\mathrm{GO}$ sheets. In the case of the $\mathrm{GO} / \mathrm{TiO}_{2}$ composite (Figure $2 b$ ), because of the island type growth mechanism, only discrete particles form on the surface instead of a continuous $\mathrm{TiO}_{2}$ film [53]. In the case of the other oxides (Figure 2c-d), the ALD nucleation is easier, and the deposited oxides form continuous films on the GO sheets [19].

Figure 3 demonstrates the powder XRD data. The peaks at $2 \Theta=10,9^{\circ}(001), 43^{\circ}(100), 23^{\circ}$ and $27^{\circ}$ are associated with the GO [54-56]. The long amorphous like baseline between $2 \Theta=10-20^{\circ}$ shows that the graphene sheets did not reassemble. The diffractograms of the $\mathrm{TiO}_{2}$ and $\mathrm{Al}_{2} \mathrm{O}_{3}$ composites do not differ from the GO, i.e., both oxides are in amorphous phase. In contrast, $\mathrm{ZnO}$ is grown in crystalline form; the additional peaks, e.g. the characteristic triple peak at $2 \Theta=35^{\circ}$ and the large peak at $2 \Theta=57^{\circ}$ in the $\mathrm{GO} / \mathrm{ZnO}$ composite are identified as wurtzite $\mathrm{ZnO}$ phase (ICDD 00-036-1451) [50,57,58]. The crystalline structure of $\mathrm{ZnO}$ as-grown by ALD is further confirmed by HRTEM and ED images recorded about the GO/ZnO sample (Figure S2).

It is well known that the TG curve of $\mathrm{GO}$ has a main mass loss step around $200^{\circ} \mathrm{C}$, showing that the functional groups are leaving from the surface $[43,59,60]$. This step is well visible on the TG/DTA curves (Figure 4.). Based on the evolved gas analysis data, first the carboxyl, epoxy and hydroxyl groups $\left(\mathrm{m} / \mathrm{z} 18^{+}, 28^{+}\right.$and $\left.44^{+}\right)$are removed, and then they are followed by the sulfonyl groups $\left(\mathrm{m} / \mathrm{z} 64^{+}\right)$. As mentioned previously, the GO has considerable $\mathrm{S}$ content originating from sulfonyl groups, which formed during the improved Hummers' preparation 
method. The oxide deposition by ALD does not change the thermal characteristics significantly (Figure $4 \mathrm{~b}-\mathrm{d}$ ). The $\mathrm{GO} / \mathrm{TiO}_{2}$ (Figure $4 \mathrm{~b}$ ) has less residual mass $\%$ at $900{ }^{\circ} \mathrm{C}$ than the bare $\mathrm{GO}$ (Figure 4a). For $\mathrm{GO} / \mathrm{Al}_{2} \mathrm{O}_{3}$ (Figure 4c) and $\mathrm{GO} / \mathrm{ZnO}$ (Figure $4 \mathrm{~d}$ ), the residual mass at $900{ }^{\circ} \mathrm{C}$ is larger than in $\mathrm{GO}$, as the oxides do not decompose.

The photocatalytic efficiency of the GO and the GO/oxide composites is compared in Figure 5. GO prepared by the improved Hummers' method and then lyophilized exhibits a clear photocatalytic effect. Immersing GO into the methyl-orange dye solution reduces the relative absorbance $\left(\mathrm{A} / \mathrm{A}_{0}\right)$ by $40 \%$ after four hours of $\mathrm{UV}$ exposition [61-63]. The $\mathrm{GO} / \mathrm{Al}_{2} \mathrm{O}_{3}$ composite is used as reference, because the $\mathrm{Al}_{2} \mathrm{O}_{3}$ itself does not have photocatalytic effect. In the corresponding composite $\mathrm{Al}_{2} \mathrm{O}_{3}$ only lowers the effectiveness of $\mathrm{GO}$ by covering and blocking active surface sites. In contrast, the photocatalytic activity of GO practically doubles when it is doped with a crystalline $\mathrm{ZnO}$ layer [50,57]. This composite reveals the highest photocatalytic activity. However, the $\mathrm{GO} / \mathrm{TiO}_{2}$ composite has a considerable efficiency as well, comparable to the $\mathrm{GO} / \mathrm{ZnO}$ composite. This is unexpected as amorphous $\mathrm{TiO}_{2}$ is considered to be photocatalytically inactive. Our finding shows that amorphous $\mathrm{TiO}_{2}$ formed by low temperature ALD on graphene oxide substrate does have a photocatalytic activity. It was reported recently that amorphous $\mathrm{TiO}_{2}$ thin films deposited on lotus leaves and $\mathrm{Si}$ sheets by low temperature ALD also displayed a photocatalytic effect [20]. The exact mechanism still needs to be elucidated. The source of the phenomenon may be, e.g. the interaction of $\mathrm{TiO}_{2}$ with the substrate, the presence of crystalline $\mathrm{TiO}_{2}$ nanodomains in the macroscopically amorphous $\mathrm{TiO}_{2}$, or impurities in $\mathrm{TiO}_{2}$ coming from the ALD reaction.

The role of the GO in the photocatalysis mechanism was reported in detail earlier in the case of GO-TiO 2 composites, and similar phenomenon iss observed in our case by the $\mathrm{GO} / \mathrm{TiO}_{2}$ and 
$\mathrm{GO} / \mathrm{ZnO}$ composites. Transfer of photogenerated electrons was observed from the conduction band of $\mathrm{TiO}_{2}$ to GO. These interacted with $\mathrm{GO}$ and could reduce certain functional groups on the surface of GO. On the other hand, holes reacting with $\mathrm{OH}$ groups on the $\mathrm{TiO}_{2}$ surface yielded $\mathrm{OH}$ radicals, which then could degrade the dye. $[9,64]$ The as-resulting charge separation contributed to an increased photocatalytic activity, compared to bare $\mathrm{GO}$ or $\mathrm{TiO}_{2}$.

To check the reproducibility of the composites, the sample with the highest activity, i.e. $\mathrm{GO} / \mathrm{ZnO}$ are further investigated. In a second round of photocatalysis with the same $\mathrm{GO} / \mathrm{ZnO}$ catalyst, there is only a few percent difference in effectiveness under UV light. It is also studied how the structure of GO might change during photocatalysis, i.e. small changes happen in the structure (Figure S3); however, these do not have significant negative effect on photocatalysis, as revealed in the repeated test.

\section{Conclusions}

In this study the application of ALD has been extended to form semiconductor oxide coatings on graphene oxide to obtain composites for photocatalytic purposes. At the used low ALD reaction temperature $\left(80^{\circ} \mathrm{C}\right)$ the $\mathrm{TiO}_{2}$ and $\mathrm{Al}_{2} \mathrm{O}_{3}$ grown on $\mathrm{GO}$ are amorphous, while a crystalline $\mathrm{ZnO}$ layer is obtained. The data reported here clearly demonstrate that GO alone, prepared by the improved Hummers' method, does show photocatalytic activity. When the photoctalytically inactive $\mathrm{Al}_{2} \mathrm{O}_{3}$ is deposited on $\mathrm{GO}$, it blocks the active surface sites of the $\mathrm{GO}$ and lowers its activity. Among the composites investigated, the $\mathrm{GO} / \mathrm{ZnO}$ has proven to be the most active; however, the amorphous $\mathrm{GO} / \mathrm{TiO}_{2}$ composite shows a comparable photocatalytic activity as well. This is in contrast with previous findings about amorphous $\mathrm{TiO}_{2}$ deposited by other methods. 
Amorphous $\mathrm{TiO}_{2}$ grown by low temperature ALD clearly has photocatalytic activity. The exact mechanism of this phenomenon is not clarified yet. Its source might be, e.g. the interaction of $\mathrm{TiO}_{2}$ with the substrate, the presence of crystalline $\mathrm{TiO}_{2}$ nanodomains in the macroscopically amorphous $\mathrm{TiO}_{2}$, or impurities in $\mathrm{TiO}_{2}$ coming from the ALD reaction. Low temperature ALD of photocatalytic amorphous $\mathrm{TiO}_{2}$ clearly has a high potential, and can be used for coating highly structured heat sensitive substrates with self-cleaning photocatalytic films.

\section{Experimental section}

\subsection{Preparation of GO suspension}

Graphene oxide (GO) was obtained by the improved Hummers' method [65] from natural graphite (Graphite Tyn, GK, China). The pristine GO suspension was purified and mildly exfoliated by centrifuging (Jouan BR4i Multifunction Centrifuge, Thermo Scientific, USA) 5 times $(7000 \mathrm{~g})$ with $1 \mathrm{M} \mathrm{HCl}$ and 6-9 times $(15100 \mathrm{~g})$ with doubly distilled water in order to remove unreacted graphite and inorganic salts. After the final washing and centrifugation step a light brown suspension with a GO nanoparticle content of $1 \mathrm{w} / \mathrm{w} \%$ was obtained.[66]

\subsection{Lyophilisation of the GO suspension}

The suspension was frozen in liquid $\mathrm{N}_{2}$. Then the pressure was reduced to $1 \mathrm{~Pa}$ and the sample was kept at $-35{ }^{\circ} \mathrm{C}$ for 3 days, allowing the frozen water in the material to sublimate. The solid GO obtained was stored at room temperature in dark. 
4.3. Atomic layer deposition on GO

$\mathrm{TiO}_{2}, \mathrm{ZnO}$ and $\mathrm{Al}_{2} \mathrm{O}_{3}$ were deposited on the freeze-dryed $\mathrm{GO}$ using $\mathrm{H}_{2} \mathrm{O}$ as well as $\mathrm{Ti}\left(\mathrm{OC}_{3} \mathrm{H}_{7}\right)_{4}$, $\mathrm{Zn}\left(\mathrm{CH}_{3}-\mathrm{CH}_{2}\right)_{2}, \mathrm{Al}\left(\mathrm{CH}_{3}\right)_{3}$ as precursors for $\mathrm{TiO}_{2}, \mathrm{ZnO}$ and $\mathrm{Al}_{2} \mathrm{O}_{3}$, respectively, in a Picosun SUNALE R-100 ALD reactor. The pulse and purge times were $0.5 \mathrm{~s}$ and $15 \mathrm{~s}$, respectively, for both the metal and $\mathrm{O}$ precursors. All the depositions were carried out at $80{ }^{\circ} \mathrm{C} .250$ ALD cycles were used for $\mathrm{TiO}_{2}$ and 100 cycles for the $\mathrm{ZnO}$ and $\mathrm{Al}_{2} \mathrm{O}_{3}$ layers.

\subsection{Characterization}

SEM-EDX data were obtained by a JEOL JSM-5500LV scanning electron microscope after sputtering an $\mathrm{Au} / \mathrm{Pd}$ layer on the samples. Au and Pd were not shown in EDX evaluation. The average EDX data reported here were calculated from 3 measured areas.

FTIR measurements were carried out in the 4000 and $400 \mathrm{~cm}^{-1}$ range on a Biorad Excalibur Series FTS 3000 infrared spectrometer. The $300 \mathrm{mg} \mathrm{KBr}$ pellets contained $1.0 \mathrm{mg}$ of the samples. 64 measurements were accumulated into one spectrum.

TEM images were taken with a JEOL 3010 transmission electron microscope operating at $300 \mathrm{keV}$. Prior to the measurements, the samples were dispersed in $\mathrm{EtOH}$, and then deposited on $\mathrm{Cu}$ grids covered with a $10 \mathrm{~nm}$ Formvar film. HRTEM and ED images were made by a FEI Technai G2 X-TWIN TEM (200 kV) device.

Powder XRD patterns were recorded on a PANanalytical X'Pert Pro MPD X-ray diffractometer using $\mathrm{Cu} \mathrm{K \alpha}$ radiation. 
TG/DTA measurements were conducted on a TA Instruments SDT 2960 simultaneous TG/DTA device in $\mathrm{He}$ atmosphere $(130 \mathrm{~mL} / \mathrm{min})$ using an open platinum crucible and $10{ }^{\circ} \mathrm{C} / \mathrm{min}$ heating rate. EGA-MS (evolved gas analytical) curves were recorded by a Balzers Instruments Thermostar GSD 200T quadruple mass spectrometer (MS) coupled on-line to the TG/DTA instrument. The on-line coupling between the two parts was provided through a heated ( $\mathrm{T}=200$ ${ }^{\circ} \mathrm{C}$ ), $100 \%$ methyl deactivated fused silica capillary tube (inner diameter of $0.15 \mathrm{~mm}$ ).

\subsection{Photocatalysis}

The photocatalytic activity of the $\mathrm{GO} /$ semiconductor oxide composites was determined from their methyl orange (MO) degradation capability under UV light. $1.0 \mathrm{mg}$ composite was suspended in $3 \mathrm{~mL} 4 \times 10^{-5} \mathrm{~mol} / \mathrm{L}$ methyl orange solution in a $4 \mathrm{~mL}$ quartz cuvette. The suspensions were kept in dark for 90 minutes to reach adsorption equilibrium (Figure S4). Then the cuvettes were placed in between two parallel UV lamps (Osram $18 \mathrm{~W} \mathrm{UV-A} \mathrm{blacklights),} \mathrm{at}$ $5 \mathrm{~cm}$ away from each lamp. The decomposition of methyl orange was followed by the absorbance of its $464 \mathrm{~nm}$ peak in every $30 \mathrm{~min}$ by a Jasco V-550 UV-VIS spectrophotometer at room temperature. To test the reproducibility of the results, after the first photocatalysis reaction with the $\mathrm{GO} / \mathrm{ZnO}$ sample, the used $\mathrm{MO}$ solution was removed and replaced with a fresh one. According to the first photocatalytic test with $\mathrm{GO} / \mathrm{ZnO}$, when $1.0 \mathrm{mg}$ composite was suspended in $3 \mathrm{~mL} 4 \times 10^{-5} \mathrm{~mol} / \mathrm{L}$ methyl orange solution, the GO- $\mathrm{ZnO}$ composite decomposed more than $80 \%$ of the dye. Due to this, only $0.4 \mathrm{mg}$ of GO-ZnO composite was suspended in $3 \mathrm{~mL} 4 \times 10^{-5}$ $\mathrm{mol} / \mathrm{L}$ methyl orange solution in the case of the reproducibility tests to get more comparable results and not to reach too low dye concentrations to measure. 


\section{Acknowledgements}

I. M. Szilágyi thanks for a János Bolyai Research Fellowship of the Hungarian Academy of Sciences and an ÚNKP-17-4-IV-BME-188 grant supported by the ÚNKP-17-4-IV New National Excellence Program of the Ministry of Human Capacities, Hungary. The research within project No. VEKOP-2.3.2-16-2017-00013 was supported by the European Union and the State of Hungary, co-financed by the European Regional Development Fund. An NRDI K 124212 and an NRDI TNN_16 123631 grants are acknowledged. The authors thank for Zsófia Baji at Hungarian Academy of Sciences, Centre for Energy Research, Institute of Technical Physics and Materials Science for the ALD reactions.

\section{Supplementary information}

SEM images and EDX data of $\mathrm{GO}, \mathrm{GO} / \mathrm{TiO}_{2}, \mathrm{GO} / \mathrm{ZnO}$ and $\mathrm{GO} / \mathrm{Al}_{2} \mathrm{O}_{3}$. HRTEM and ED images of $\mathrm{GO} / \mathrm{ZnO}$. XRD patterns of $\mathrm{GO} / \mathrm{ZnO}$ before and after photocatalysis. Dark adsorption data of the studied photocatalytic materials.

\section{References}

[1] Z.-D. Meng, F.-J. Zhang, L. Zhu, C.-Y. Park, T. Ghosh, J.-G. Choi, W.-C. Oh, Synthesis and characterization of $\mathrm{M}$-fullerene/TiO2 photocatalysts designed for degradation azo dye, Mater. Sci. Eng. C. 32 (2012) 2175-2182. doi:10.1016/j.msec.2012.05.048.

[2] V. Apostolopoulou, J. Vakros, C. Kordulis, A. Lycourghiotis, Preparation and 
characterization of [60] fullerene nanoparticles supported on titania used as a photocatalyst, Colloids Surfaces A Physicochem. Eng. Asp. 349 (2009) 189-194. http://www.sciencedirect.com/science/article/pii/S0927775709005019 (accessed October $5,2013)$.

[3] M.R. Hoffmann, S.T. Martin, W. Choi, D.W. Bahnemann, Environmental Applications of Semiconductor Photocatalysis, Chem. Rev. 95 (1995) 69-96. doi:10.1021/cr00033a004.

[4] K. Nakata, A. Fujishima, TiO2 photocatalysis: Design and applications, J. Photochem. $\begin{array}{llllll}\text { Photobiol. } & \text { C } & \text { Photochem. } & \text { Rev. } & 13 & \text { (2012) }\end{array}$ doi:10.1016/j.jphotochemrev.2012.06.001.

[5] O. Czakkel, E. Geissler, I.M. Szilágyi, K. László, TiO2-doped resorcinol-formaldehyde (RF) polymer and carbon gels with photocatalytic activity, Nanomater. Environ. 1 (2013) 23-30. doi:10.2478/nanome-2013-0001.

[6] R. Leary, A. Westwood, Carbonaceous nanomaterials for the enhancement of $\mathrm{TiO} 2$ $\begin{array}{lllllll}\text { photocatalysis, } & \text { Carbon } & \text { N. } & \text { Y. } & 49 & \text { (2011) } & \text { 741-772. }\end{array}$ http://www.sciencedirect.com/science/article/pii/S0008622310007207_ (accessed September 24, 2013).

[7] G. Liu, L. Wang, H.G. Yang, H.-M. Cheng, G.Q. (Max) Lu, Titania-based photocatalysts - crystal growth, doping and heterostructuring, J. Mater. Chem. 20 (2010) 831-843. doi:10.1039/B909930A.

[8] A.L. Linsebigler, G. Lu, J.T. Yates, Photocatalysis on TiOn Surfaces: Principles, Mechanisms, and Selected Results, Chem. Rev. 95 (1995) 735-758. doi:10.1021/cr00035a013.

[9] L. Zhang, Q. Zhang, H. Xie, J. Guo, H. Lyu, Y. Li, Z. Sun, H. Wang, Z. Guo, Electrospun 
titania nanofibers segregated by graphene oxide for improved visible light photocatalysis, Appl. Catal. B Environ. 201 (2017) 470-478. doi:10.1016/j.apcatb.2016.08.056.

[10] C. Han, N. Zhang, Y.J. Xu, Structural diversity of graphene materials and their multifarious roles in heterogeneous photocatalysis, Nano Today. 11 (2016) 351-372. doi:10.1016/j.nantod.2016.05.008.

[11] S. Perathoner, C. Ampelli, S. Chen, R. Passalacqua, D. Su, G. Centi, Photoactive materials based on semiconducting nanocarbons - A challenge opening new possibilities for photocatalysis, J. Energy Chem. 26 (2017) 207-218. doi:10.1016/j.jechem.2017.01.005.

[12] T. Jayaraman, A. Prasad, V. Elakkiya, M. Jagannathan, M. Ashokkumar, Journal of Industrial and Engineering Chemistry Recent development on carbon based heterostructures for their applications in energy and environment : A review, J. Ind. Eng. Chem. (2018). doi:10.1016/j.jiec.2018.02.029.

[13] D. Channei, A. Nakaruk, S. Phanichphant, Influence of graphene oxide on photocatalytic enhancement of cerium dioxide, Mater. Lett. 209 (2017) 43-47. doi:10.1016/j.matlet.2017.07.109.

[14] A. Datcu, M.L. Mendoza, A.P. del Pino, C. Logofatu, C. Luculescu, E. György, UVvisible light induced photocatalytic activity of $\mathrm{TiO} 2$ /graphene oxide nanocomposite coatings, Catal. Today. (2018) 0-1. doi:10.1016/J.CATTOD.2018.02.026.

[15] S. Cao, C. Chen, J. Zhang, C. Zhang, W. Yu, B. Liang, Y. Tsang, MnOxquantum dots decorated reduced graphene oxide/TiO2nanohybrids for enhanced activity by a UV precatalytic microwave method, Appl. Catal. B Environ. 176-177 (2015) 500-512. doi:10.1016/j.apcatb.2015.04.041.

[16] S. Cao, T. Liu, Y. Tsang, C. Chen, Role of hydroxylation modification on the structure 
and property of reduced graphene oxide/TiO2 hybrids, Appl. Surf. Sci. 382 (2016) 225238. doi:10.1016/J.APSUSC.2016.04.138.

[17] J. Wei, Z. Zang, Y. Zhang, M. Wang, J. Du, X. Tang, Enhanced performance of lightcontrolled conductive switching in hybrid cuprous oxide/reduced graphene oxide (Cu_2O/rGO) nanocomposites, Opt. Lett. 42 (2017) 911. doi:10.1364/OL.42.000911.

[18] Z. Zang, X. Zeng, M. Wang, W. Hu, C. Liu, X. Tang, Tunable photoluminescence of water-soluble AgInZnS-graphene oxide (GO) nanocomposites and their application invivo bioimaging, Sensors Actuators B Chem. 252 (2017) 1179-1186. doi:10.1016/j.snb.2017.07.144.

[19] C. Marichy, N. Pinna, Carbon-nanostructures coated/decorated by atomic layer deposition: Growth and applications, Coord. Chem. Rev. 257 (2013) 3232-3253. doi:10.1016/j.ccr.2013.08.007.

[20] I.M. Szilágyi, G. Teucher, E. Härkönen, E. Färm, T. Hatanpää, T. Nikitin, L. Khriachtchev, M. Räsänen, M. Ritala, M. Leskelä, Programming nanostructured soft biological surfaces by atomic layer deposition., Nanotechnology. 24 (2013) 245701. doi:10.1088/0957-4484/24/24/245701.

[21] M. Knez, K. Nielsch, L. Niinistö, Synthesis and Surface Engineering of Complex Nanostructures by Atomic Layer Deposition, Adv. Mater. 19 (2007) 3425-3438. doi:10.1002/adma.200700079.

[22] A. Nourbakhsh, C. Adelmann, Y. Song, C.S. Lee, I. Asselberghs, C. Huyghebaert, S. Brizzi, M. Tallarida, D. Schmeisser, S. Van Elshocht, M. Heyns, J. Kong, T. Palacios, S. De Gendt, Graphene oxide monolayers as atomically thin seeding layers for atomic layer deposition of metal oxides., Nanoscale. 7 (2015) 10781-9. doi:10.1039/c5nr01128k. 
[23] H. Zhang, S. Shuang, G. Wang, Y. Guo, X. Tong, P. Yang, A. Chen, C. Dong, Y. Qin, TiO 2 -graphene hybrid nanostructures by atomic layer deposition with enhanced electrochemical performance for $\mathrm{Pb}$ ( ii ) and $\mathrm{Cd}$ ( ii ) detection, RSC Adv. 5 (2015) 4343 4349. doi:10.1039/C4RA09779C.

[24] L. Yang, L. Jiang, W. Fu, A.W. Weimer, X. Hu, Y. Zhou, TiO2 quantum dots grown on graphene by atomic layer deposition as advanced photocatalytic hybrid materials, Appl. Phys. A. 123 (2017) 416. doi:10.1007/s00339-017-1018-y.

[25] C. Ban, M. Xie, X. Sun, J.J. Travis, G. Wang, H. Sun, A.C. Dillon, J. Lian, S.M. George, Atomic layer deposition of amorphous $\mathrm{TiO}_{2}$ on graphene as an anode for $\mathrm{Li}$-ion batteries, Nanotechnology. 24 (2013) 424002. doi:10.1088/0957-4484/24/42/424002.

[26] J.A. Robinson, M. LaBella, K.A. Trumbull, X. Weng, R. Cavelero, T. Daniels, Z. Hughes, M. Hollander, M. Fanton, D. Snyder, Epitaxial Graphene Materials Integration: Effects of Dielectric Overlayers on Structural and Electronic Properties, ACS Nano. 4 (2010) 26672672. doi:10.1021/nn1003138.

[27] Y. Zhang, C. Guerra-Nuñez, I. Utke, J. Michler, P. Agrawal, M.D. Rossell, R. Erni, Atomic Layer Deposition of Titanium Oxide on Single-Layer Graphene: An Atomic-Scale Study toward Understanding Nucleation and Growth, Chem. Mater. 29 (2017) 2232-2238. doi:10.1021/acs.chemmater.6b05143.

[28] D.S. Shin, H.G. Kim, H.S. Ahn, H.Y. Jeong, Y.-J. Kim, D. Odkhuu, N. Tsogbadrakh, H.B.-R. Lee, B.H. Kim, Distribution of oxygen functional groups of graphene oxide obtained from low-temperature atomic layer deposition of titanium oxide, RSC Adv. 7 (2017) 13979-13984. doi:10.1039/C7RA00114B.

[29] M. Li, X. Li, W. Li, X. Meng, Y. Yu, X. Sun, Atomic layer deposition derived amorphous 
TiO 2 thin film decorating graphene nanosheets with superior rate capability, Electrochem. Commun. 57 (2015) 43-47. doi:10.1016/j.elecom.2015.05.005.

[30] C. a Merchant, K. Healy, M. Wanunu, V. Ray, N. Peterman, J. Bartel, M.D. Fischbein, K. Venta, Z. Luo, a T.C. Johnson, M. Drndić, DNA translocation through graphene nanopores., Nano Lett. 10 (2010) 2915-21. doi:10.1021/nl101046t.

[31] C.-T. Hsieh, W.-Y. Chen, D.-Y. Tzou, A.K. Roy, H.-T. Hsiao, Atomic layer deposition of Pt nanocatalysts on graphene oxide nanosheets for electro-oxidation of formic acid, Int. J. Hydrogen Energy. 37 (2012) 17837-17843. doi:10.1016/j.ijhydene.2012.08.139.

[32] N. Justh, T. Firkala, K. László, J. Lábár, I.M. Szilágyi, Photocatalytic C60-amorphous TiO2 composites prepared by atomic layer deposition, Appl. Surf. Sci. 419 (2017) 497502. doi:10.1016/J.APSUSC.2017.04.243.

[33] M.-Q. Yang, N. Zhang, M. Pagliaro, Y.-J. Xu, Artificial photosynthesis over graphenesemiconductor composites. Are we getting better?, Chem. Soc. Rev. 43 (2014) 82408254. doi:10.1039/C4CS00213J.

[34] Q. Xiang, J. Yu, M. Jaroniec, Graphene-based semiconductor photocatalysts., Chem. Soc. Rev. 41 (2012) 782-96. doi:10.1039/c1cs15172j.

[35] D.A. Dikin, S. Stankovich, E.J. Zimney, R.D. Piner, G.H.B. Dommett, G. Evmenenko, S.T. Nguyen, R.S. Ruoff, Preparation and characterization of graphene oxide paper., Nature. 448 (2007) 457-60. doi:10.1038/nature06016.

[36] M.-Q. Yang, N. Zhang, Y. Wang, Y.-J. Xu, Metal-free, robust, and regenerable 3D graphene-organics aerogel with high and stable photosensitization efficiency, J. Catal. 346 (2017) 21-29. doi:10.1016/J.JCAT.2016.11.012.

[37] K.-Q. Lu, N. Zhang, C. Han, F. Li, Z. Chen, Y.-J. Xu, Insight into the Origin of Boosted 
Photosensitive Efficiency of Graphene from the Cooperative Experiment and Theory Study, J. Phys. Chem. C. 120 (2016) 27091-27103. doi:10.1021/acs.jpcc.6b06829.

[38] N. Zhang, M.-Q. Yang, S. Liu, Y. Sun, Y.-J. Xu, Waltzing with the Versatile Platform of Graphene to Synthesize Composite Photocatalysts, Chem. Rev. 115 (2015) 10307-10377. doi:10.1021/acs.chemrev.5b00267.

[39] G. Torrisi, A. Di Mauro, M. Scuderi, G. Nicotra, G. Impellizzeri, Atomic layer deposition of $\mathrm{ZnO} / \mathrm{TiO}_{2}$ multilayers: towards the understanding of Ti-doping in $\mathrm{ZnO}$ thin films, $\mathrm{RSC}$ Adv. 6 (2016) 88886-88895. doi:10.1039/C6RA13773C.

[40] K. Krishnamoorthy, R. Mohan, S.J. Kim, Graphene oxide as a photocatalytic material, Appl. Phys. Lett. 98 (2011) 2013-2016. doi:10.1063/1.3599453.

[41] J. Guerrero-Contreras, F. Caballero-Briones, Graphene oxide powders with different oxidation degree, prepared by synthesis variations of the Hummers method, Mater. Chem. Phys. 153 (2015) 209-220. doi:10.1016/j.matchemphys.2015.01.005.

[42] S. Eigler, C. Dotzer, F. Hof, W. Bauer, A. Hirsch, Sulfur species in graphene oxide., Chemistry. 19 (2013) 9490-6. doi:10.1002/chem.201300387.

[43] B. Erdem, R. a Hunsicker, G.W. Simmons, E.D. Sudol, V.L. Dimonie, M.S. El-aasser, XPS and FTIR Surface Characterization of TiO2 Particles Used in Polymer Encapsulation, Langmuir. 17 (2001) 2664-2669. doi:10.1021/la0015213.

[44] A. Adamczyk, E. Długoń, The FTIR studies of gels and thin films of Al2O3-TiO2 and Al2O3-TiO2-SiO2 systems, Spectrochim. Acta Part A Mol. Biomol. Spectrosc. 89 (2012) 11-17. doi:10.1016/j.saa.2011.12.018.

[45] H. Kumar, R. Rani, Structural and Optical Characterization of $\mathrm{ZnO}$ Nanoparticles Synthesized by Microemulsion Route, 14 (2013) 26-36. 
[46] T. P, I \& a-red spectra of inorganic aluminates and characteristic vibrational frequencies of AlO tetrahedra and AlOs octahedra, Spectrochim. Acta. 23 (1967) 2127-2143.

[47] A.H. Heuer, T. Nakagawa, M.Z. Azar, D.B. Hovis, J.L. Smialek, B. Gleeson, ScienceDirect On the growth of Al 2 O 3 scales q, Acta Mater. 61 (2013) 6670-6683. doi:10.1016/j.actamat.2013.07.024.

[48] X. Huang, Z. Chen, T. Gao, Q. Huang, F. Niu, L. Qin, Y. Huang, Hydrogen Generation by Hydrolysis of an $\mathrm{Al} / \mathrm{Al}_{2} \mathrm{O}_{3}$-Composite Powder After Heat Treatment, Energy Technol. 1 (2013) 751-756. doi:10.1002/ente.201300129.

[49] H.N. Tien, V.H. Luan, L.T. Hoa, N.T. Khoa, S.H. Hahn, J.S. Chung, E.W. Shin, S.H. Hur, One-pot synthesis of a reduced graphene oxide-zinc oxide sphere composite and its use as a visible light photocatalyst, Chem. Eng. J. 229 (2013) 126-133. doi:10.1016/j.cej.2013.05.110.

[50] A. Pruna, Z. Wu, J.A. Zapien, Y.Y. Li, A. Ruotolo, Enhanced photocatalytic performance of $\mathrm{ZnO}$ nanostructures by electrochemical hybridization with graphene oxide, Appl. Surf. Sci. 441 (2018) 936-944. doi:10.1016/j.apsusc.2018.02.117.

[51] J. Hu, H. Li, Q. Wu, Y. Zhao, Q. Jiao, Synthesis of TiO2 nanowire/reduced graphene oxide nanocomposites and their photocatalytic performances, Chem. Eng. J. 263 (2015) 144-150. doi:10.1016/j.cej.2014.11.007.

[52] H. Wu, J. Fan, E. Liu, X. Hu, Y. Ma, X. Fan, Y. Li, C. Tang, Facile hydrothermal synthesis of $\mathrm{TiO} 2$ nanospindles-reduced graphene oxide composite with a enhanced photocatalytic activity, J. Alloys Compd. 623 (2015) 298-303. doi:10.1016/j.jallcom.2014.10.153.

[53] J. Dendooven, S. Pulinthanathu Sree, K. De Keyser, D. Deduytsche, J.A. Martens, K.F. 
Ludwig, C. Detavernier, In Situ X-ray Fluorescence Measurements During Atomic Layer Deposition: Nucleation and Growth of $\mathrm{TiO}_{2}$ on Planar Substrates and in Nanoporous Films, J. Phys. Chem. C. 115 (2011) 6605-6610. doi:10.1021/jp111314b.

[54] Z.-B. Zhang, J.-J. Wu, Y. Su, J. Zhou, Y. Gao, H.-Y. Yu, J.-S. Gu, Layer-by-layer assembly of graphene oxide on polypropylene macroporous membranes via click chemistry to improve antibacterial and antifouling performance, Appl. Surf. Sci. 332 (2015) 300-307. doi:10.1016/j.apsusc.2015.01.193.

[55] L. Stobinski, B. Lesiak, a. Malolepszy, M. Mazurkiewicz, B. Mierzwa, J. Zemek, P. Jiricek, I. Bieloshapka, Graphene oxide and reduced graphene oxide studied by the XRD, TEM and electron spectroscopy methods, J. Electron Spectros. Relat. Phenomena. 195 (2014) 145-154. doi:10.1016/j.elspec.2014.07.003.

[56] M. Sun, W. Li, S. Sun, J. He, Q. Zhang, Y. Shi, One-step in situ synthesis of grapheneTiO2 nanorod hybrid composites with enhanced photocatalytic activity, Mater. Res. Bull. 61 (2015) 280-286. doi:10.1016/j.materresbull.2014.10.040.

[57] C. Chen, W. Yu, T. Liu, S. Cao, Y. Tsang, Graphene oxide/WS2/Mg-doped ZnO nanocomposites for solar-light catalytic and anti-bacterial applications, Sol. Energy Mater. Sol. Cells. 160 (2017) 43-53. doi:10.1016/j.solmat.2016.10.020.

[58] R. Liu, M. Peng, H. Zhang, X. Wan, M. Shen, Atomic layer deposition of ZnO on graphene for thin film transistor, Mater. Sci. Semicond. Process. 56 (2016) 324-328. doi:10.1016/j.mssp.2016.09.016.

[59] S. Stankovich, D. a. Dikin, R.D. Piner, K. a. Kohlhaas, A. Kleinhammes, Y. Jia, Y. Wu, S.T. Nguyen, R.S. Ruoff, Synthesis of graphene-based nanosheets via chemical reduction of exfoliated graphite oxide, Carbon N. Y. 45 (2007) 1558-1565. 
doi:10.1016/j.carbon.2007.02.034.

[60] C. Botas, P. Álvarez, P. Blanco, M. Granda, C. Blanco, R. Santamaría, L.J. Romasanta, R. Verdejo, M. a. López-Manchado, R. Menéndez, Graphene materials with different structures prepared from the same graphite by the Hummers and Brodie methods, Carbon N. Y. 65 (2013) 156-164. doi:10.1016/j.carbon.2013.08.009.

[61] H.-C. Hsu, I. Shown, H.-Y. Wei, Y.-C. Chang, H.-Y. Du, Y.-G. Lin, C.-A. Tseng, C.-H. Wang, L.-C. Chen, Y.-C. Lin, K.-H. Chen, Graphene oxide as a promising photocatalyst for CO2 to methanol conversion., Nanoscale. 5 (2013) 262-8. doi:10.1039/c2nr31718d.

[62] K. Krishnamoorthy, M. Veerapandian, R. Mohan, S.-J. Kim, Investigation of Raman and photoluminescence studies of reduced graphene oxide sheets, Appl. Phys. A. 106 (2011) 501-506. doi:10.1007/s00339-011-6720-6.

[63] T.-F. Yeh, J. Cihláŕ, C.-Y. Chang, C. Cheng, H. Teng, Roles of graphene oxide in photocatalytic water splitting, Mater. Today. 16 (2013) 78-84. doi:10.1016/j.mattod.2013.03.006.

[64] G. Williams, B. Seger, P. V. Kamat, TiO 2 -Graphene Nanocomposites. UV-Assisted Photocatalytic Reduction of Graphene Oxide, ACS Nano. 2 (2008) 1487-1491. doi:10.1021/nn800251f.

[65] D.C. Marcano, D. V Kosynkin, J.M. Berlin, A. Sinitskii, Z. Sun, A. Slesarev, L.B. Alemany, W. Lu, J.M. Tour, Improved Synthesis of Graphene Oxide, ACS Nano. 4 (2010) 4806-4814.

[66] N. Justh, B. Berke, K. László, I.M. Szilágyi, Thermal analysis of the improved Hummers' synthesis of graphene oxide, J. Therm. Anal. Calorim. (2017). doi:10.1007/s10973-0176697-2. 


\section{Figures}

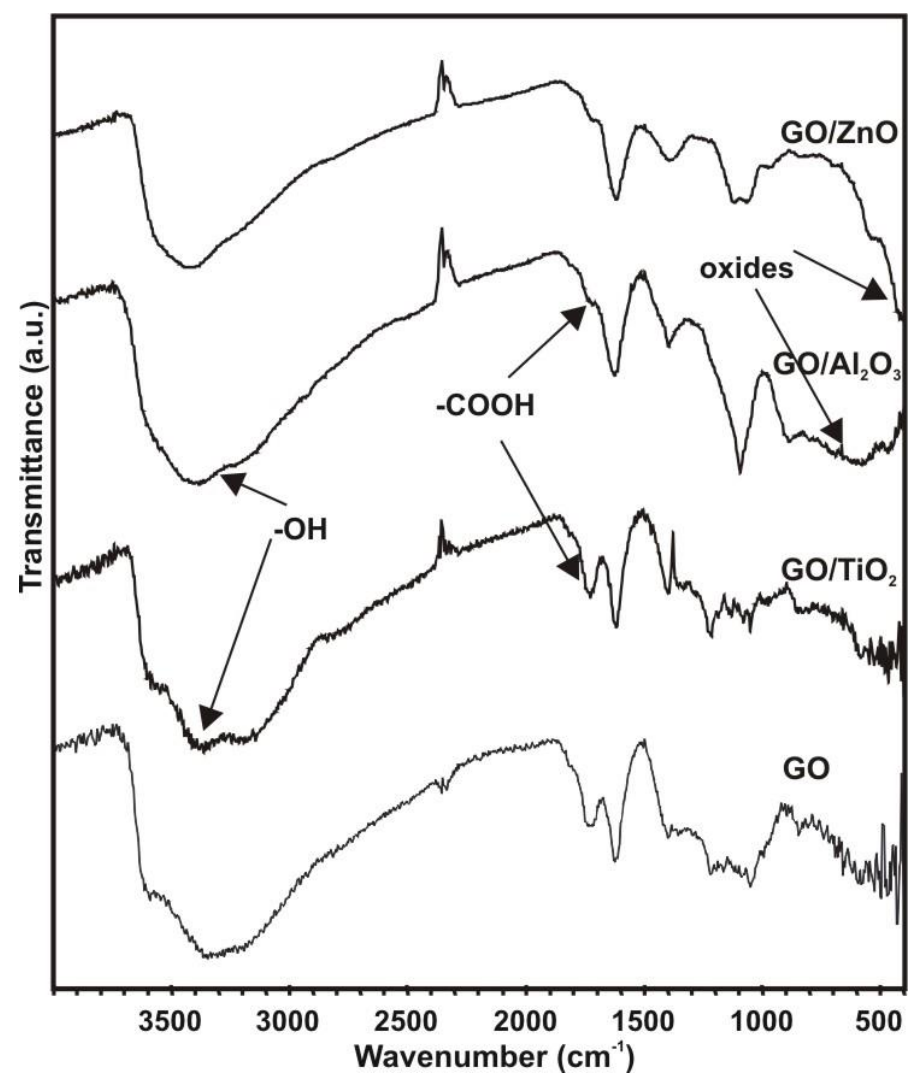

Figure 1. FTIR spectra of $\mathrm{GO}, \mathrm{GO} / \mathrm{TiO}_{2}, \mathrm{GO} / \mathrm{ZnO}$ and $\mathrm{GO} / \mathrm{Al}_{2} \mathrm{O}_{3}$ 


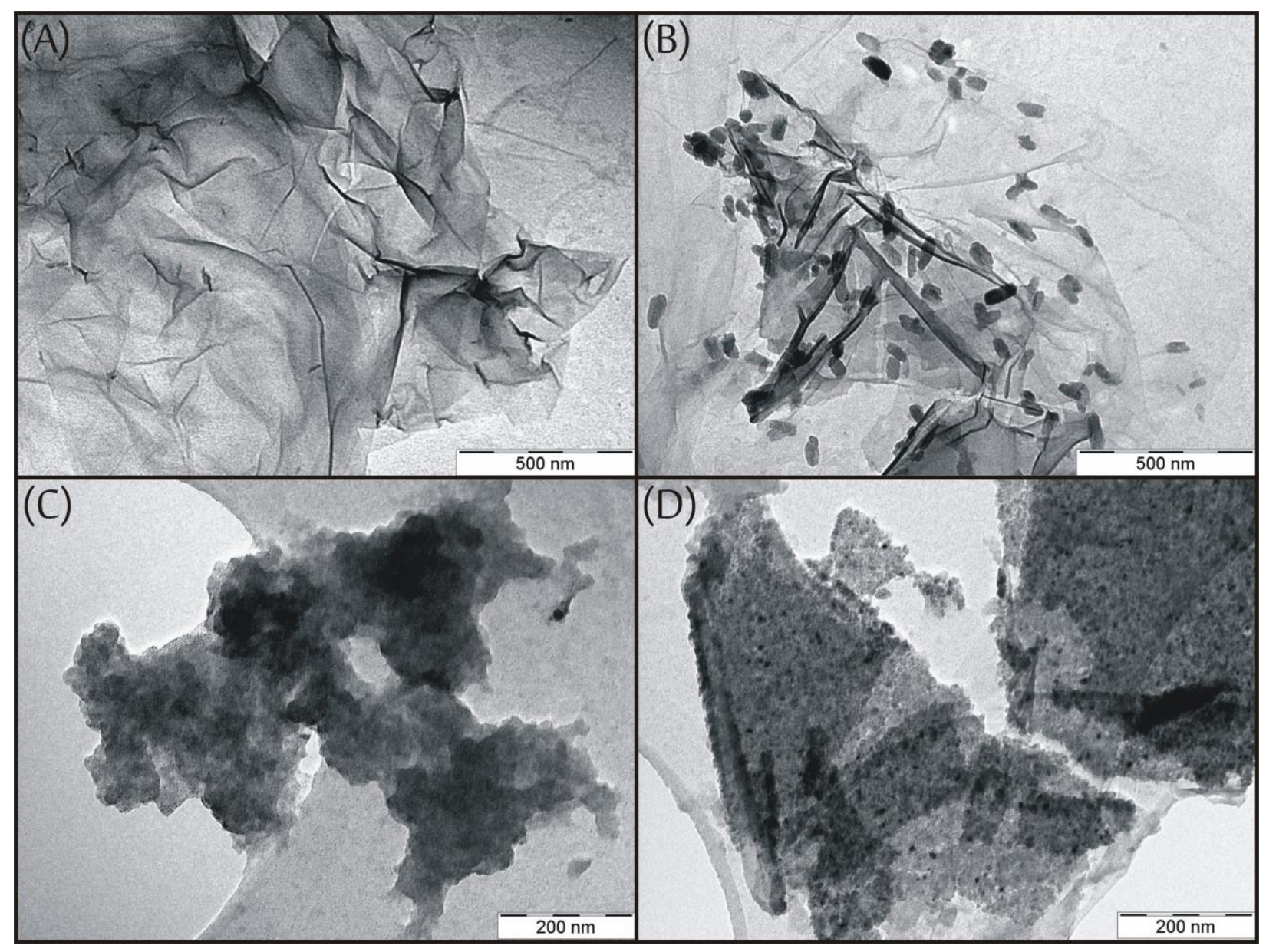

Figure 2. TEM images of (A): $\mathrm{GO}$, (B): $\mathrm{GO} / \mathrm{TiO}_{2},(\mathrm{C}): \mathrm{GO} / \mathrm{Al}_{2} \mathrm{O}_{3}$ and (D): $\mathrm{GO} / \mathrm{ZnO}$ 


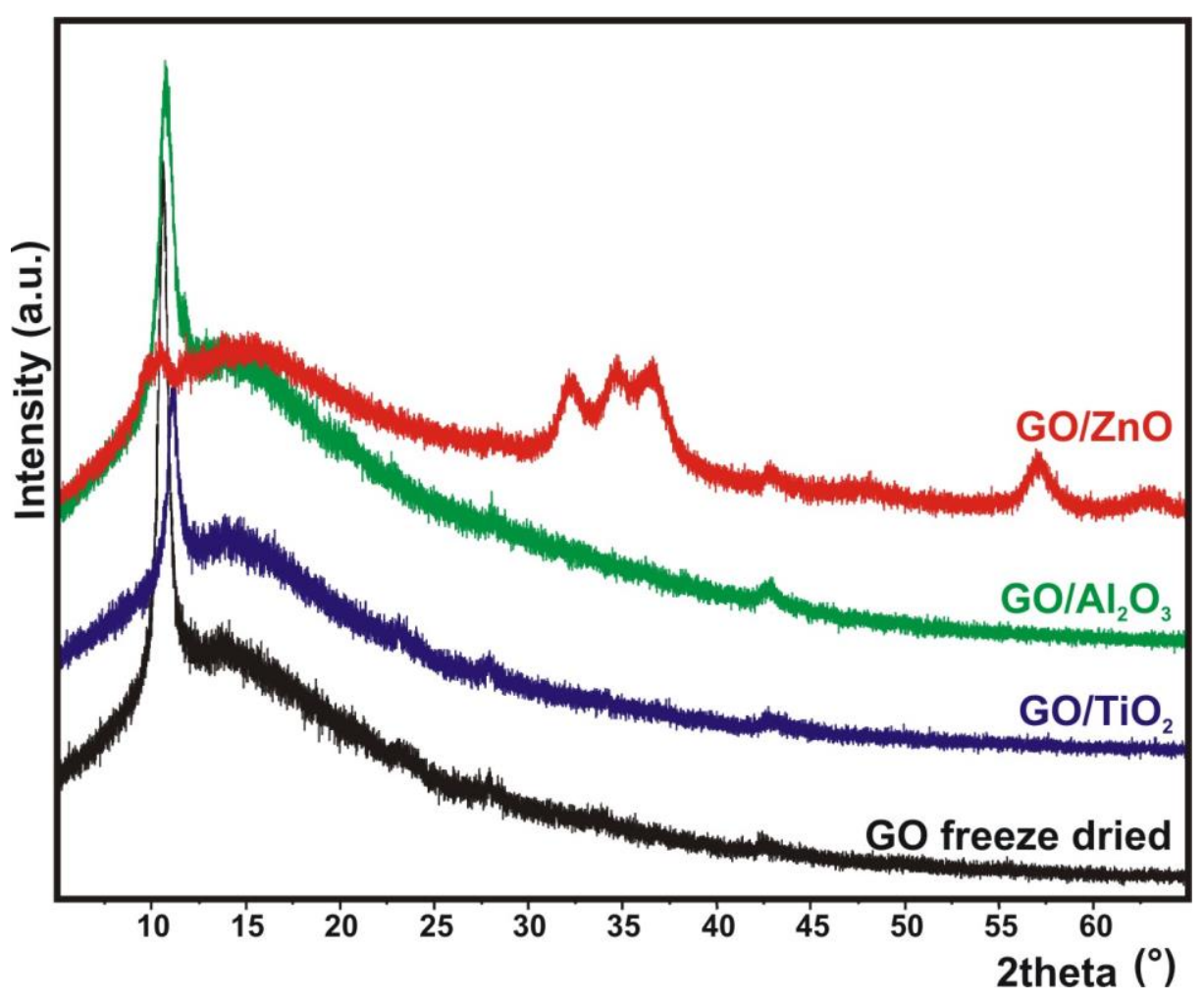

Figure 3. $\mathrm{XRD}$ diffractograms of $\mathrm{GO}, \mathrm{GO} / \mathrm{TiO}_{2}, \mathrm{GO} / \mathrm{ZnO}$ and $\mathrm{GO} / \mathrm{Al}_{2} \mathrm{O}_{3}$ 

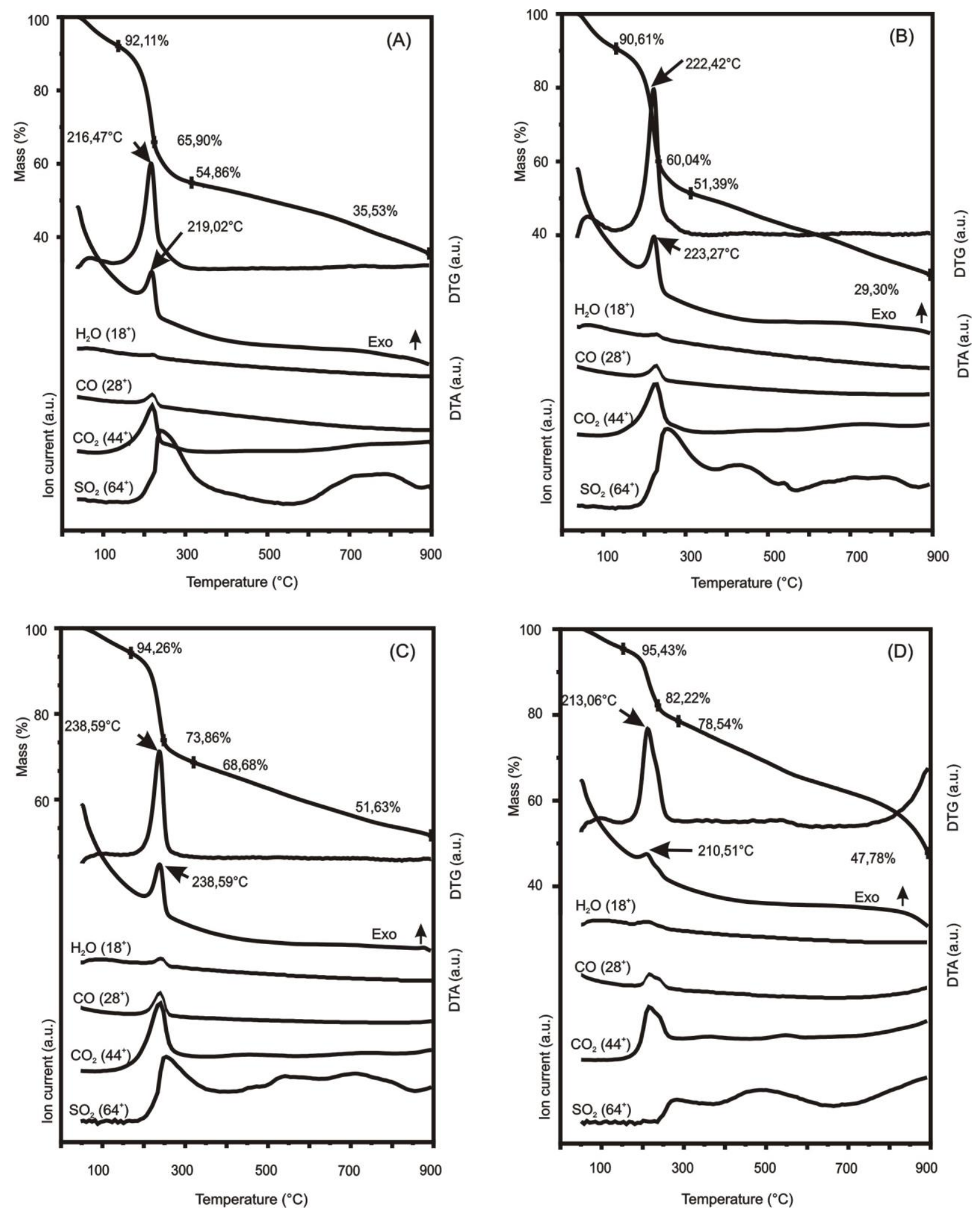

Figure 4. TG/DTA-MS results in $\mathrm{He}$ atmosphere: (A): $\mathrm{GO},(\mathrm{B}): \mathrm{GO} / \mathrm{TiO}_{2},(\mathrm{C}): \mathrm{GO} / \mathrm{Al}_{2} \mathrm{O}_{3}$, (D): $\mathrm{GO} / \mathrm{ZnO}$. 


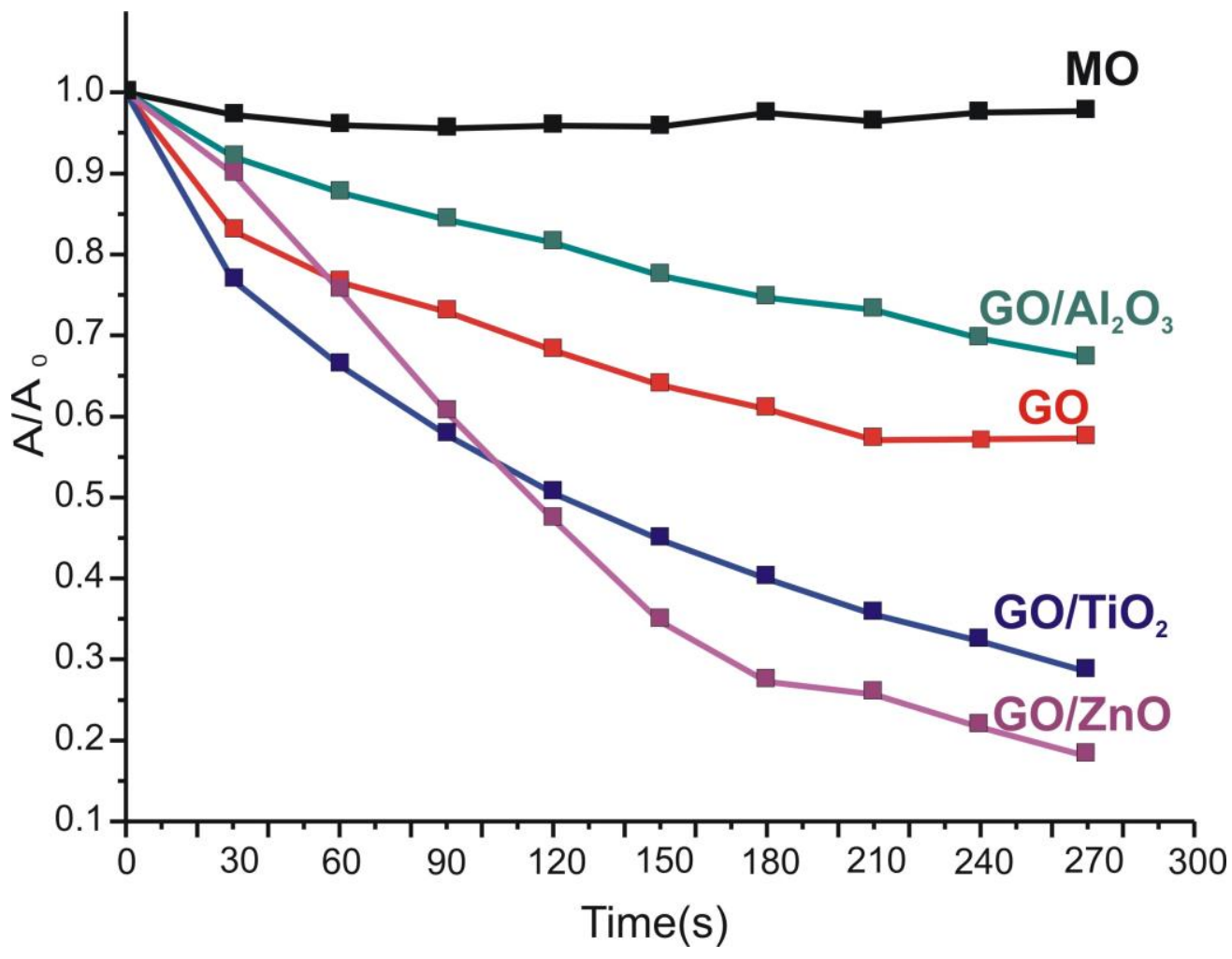

Figure 5. Photocatalytic results of $\mathrm{GO} ; \mathrm{GO} / \mathrm{TiO}_{2}, \mathrm{GO} / \mathrm{ZnO}$ and $\mathrm{GO} / \mathrm{Al}_{2} \mathrm{O}_{3}$ composites; $\mathrm{MO}$ shows the degradation of methyl orange without catalyst at room temperature 


\section{Tables}

\begin{tabular}{|c|c|c|c|c|c|c|}
\hline \multicolumn{7}{|c|}{ Element (atom \%) } \\
\hline Sample & $\mathrm{C}$ & $\mathrm{O}$ & $\mathrm{S}$ & $\mathrm{Ti}$ & $\mathrm{Al}$ & $\mathrm{Zn}$ \\
\hline \hline $\mathrm{GO}$ & 64.95 & 34.25 & 0.69 & & & \\
\hline $\mathrm{GO} / \mathrm{TiO}_{2}$ & 63.97 & 34.91 & 0.34 & 0.75 & & \\
\hline $\mathrm{GO} / \mathrm{Al}_{2} \mathrm{O}_{3}$ & 59.94 & 30.34 & 0.86 & & 11.85 & \\
\hline $\mathrm{GO} / \mathrm{ZnO}$ & 59.10 & 29.34 & 0.58 & & & 10.06 \\
\hline
\end{tabular}

Table 1. EDX data of $\mathrm{GO}$ as well as $\mathrm{GO} / \mathrm{TiO}_{2}, \mathrm{GO} / \mathrm{ZnO}$ and $\mathrm{GO} / \mathrm{Al}_{2} \mathrm{O}_{3}$ composites 